\title{
O BANCO NACIONAL DE DESENVOLVIMENTO ECONÔMICO E SOCIAL (BNDES) E A EXPANSÃO DE EMPRESAS BRASILEIRAS DE CONSTRUÇÃO CIVIL PARA A AMÉRICA DO SUL ${ }^{1}$
}

\author{
Elsa Sousa Kraychete*
}

\begin{abstract}
Este artigo apresenta os contratos de créditos concedidos pelo Banco Nacional de Desenvolvimento Econômico e Social, entre 2004 e 2015, orientados para apoiar a exportação de serviços de engenharia para países da América do Sul, discriminados por empresa, país, obra realizada e valor do contrato. A análise dos dados é acompanhada da historicização das mudanças institucionais por que passa o Banco nas últimas décadas. A conclusão é que a concessão de créditos a empresas brasileiras de construção civil para a realização de obras no exterior é resultado de amplo movimento que contempla: exigências de sintonia entre os processos de valorização dos capitais e o modo de regulação diante das amplas modificações que o capitalismo passou em período recente; ações governamentais orientadas pela decisão de intensificar as relações Sul-Sul, especialmente em relação aos países da porção Sul do continente americano; e estratégias empresariais que visam a ampliação dos espaços de atuação.
\end{abstract}

Palavras chave: Banco Nacional de Desenvolvimento Econômico e Social. Crédito. Empresas de construção civil. Brasil. América do Sul.

\section{INTRODUÇÃO}

O Banco Nacional de Desenvolvimento Econômico e Social (BNDES), fundado em 1952 e, ainda hoje, o principal ofertante de créditos de investimentos de longo prazo no Brasil, passou, no decorrer das últimas décadas, por reorganização estrutural associada às exigências colocadas para uma instituição de créditos diante de uma conjuntura que visava a sintonizar o capitalismo amplamente reformado com um sistema de regulação condizente. Em termos mais específicos, as reformas estruturais do aparelho de Estado, inclusive a reestruturação patrimonial, como se verificou no ciclo de privatizações de empresas estatais

* Universidade Federal da Bahia (UFBA). Instituto de Artes e Humanidades.

Rua Barão de Geremoabo s/n. Ondina. Cep: 40170-240. Salvador - Bahia - Brasil. ekraychete@gmail.com

${ }^{1}$ Este artigo traz parte dos resultados do Projeto Cooperação Sul-Sul: um estudo sobre dinâmicas socioeconômicas, políticas, científicas, culturais e ambientais na América do Sul a partir do caso do Brasil, no eixo que analisa o papel do capital financeiro em sua vertente estatal para a internacionalização das empresas e montagem da infraestrutura na perspectiva da integração sul-americana (Edital FAPESB/CNPq no. 028/2010 - PRONEM). São também integrantes desse eixo do projeto Rômulo Cristaldo, doutorando do Núcleo de Pós-Graduação em Administração e Dandara Lima, bolsista de Iniciação Científica. na virada para os anos 2000, que ampliam as fronteiras de contato entre o Banco e empresas privadas, são os aspectos mais destacados que justificam as mudanças no BNDES.

As mudanças na política externa brasileira, timidamente iniciadas na década de 1990 e que ganham maior impulso a partir do governo de Lula da Silva (2003-2010), enfatizam as relações diplomáticas, tanto no âmbito da articulação política como em ações em favor do estreitamento de relações econômicas no eixo Sul-Sul, e também repercutem no BNDES, orientando que a organização reforce mudanças em sua estrutura e no âmbito das suas operações. Nesse movimento, a América do Sul é eleita como área prioritária das relações externas brasileiras, com iniciativas que visam a fortalecer os mecanismos de cooperação política regional, como também o adensamento de um espaço econômico com fortalecimento do comércio intrarregional, de investimentos produtivos e montagem da infraestrutura física. Esse movimento da política externa brasileira também repercute no BNDES, justificando um reordenamento institucional.

As dinâmicas internas da economia bra- 
sileira, com seus respectivos posicionamentos na economia internacional, influenciam a atuação do Banco, o que permite identificar duas fases de atuação ao longo da sua trajetória: a primeira, entre 1952 a 1979, corresponde ao período marcado por forte presença governamental, com a apresentação de planos econômicos centrados no desenvolvimento da infraestrutura econômica e o intuito de montar uma matriz industrial com coerência entre setores produtivos no interior da economia brasileira; a segunda, a partir do fim dos anos 1970, com reorientação macroeconômica voltada para o ajuste das contas internas e externas e reestruturação patrimonial do Estado. Enquanto, na primeira fase, a coordenação econômica estava voltada para o desenvolvimento da indústria e do mercado interno, na segunda, as estratégias desenvolvimentistas perdem fôlego, cedendo lugar às políticas de ajuste macroeconômico e reformas estruturais. Nessa última fase, marcada pela liberalização dos mercados, o governo brasileiro define novas estratégias geopolíticas que vão imprimir redirecionamentos na atuação da instituição em foco, com inflexões importantes.

Este texto se ocupa da análise do segundo período, ${ }^{2}$ com destaque para as mudanças organizacionais por que passa o Banco e para a expansão de empresas brasileiras da construção civil na execução de obras em países da América do Sul.

\section{REDEFINIÇÕES ESTRATÉGICAS E REFORMAS ORGANIZACIONAIS PARA ATUAÇÃO DO BNDES A PAR- TIR DOS ANOS 1990}

As redefinições e reformas na atuação do BNDES estão associadas ao movimento que recomendava a desregulação e a abertura dos

${ }^{2}$ Uma análise detalhada da trajetória do BNDES pode ser encontrada em KRAYCHETE, Elsa Sousa e CRISTALDO, Rômulo Carvalho. The National Bank of Economic and Social Development on the Brazilian Development strategies: from internal articulation to expansion to Latin America. Geopolitica(s): revista de estudios sobre espacio y poder, v. 4, 2013. mercados, o financeiro incluso, e dos investimentos das economias nacionais, mas cotejadas com as redefinições estratégicas da geopolítica brasileira. Se tomado apenas o primeiro movimento, a existência de bancos nacionais de desenvolvimento ${ }^{3}$ esteve em questão, com proposições de extinções recomendadas. No Brasil, essa recomendação, no entanto, não gozava de consenso entre formuladores de política econômica, setores empresariais e governantes. A reafirmação da importância de uma instituição especializada em financiamentos de longo prazo, na redefinição dos caminhos do crescimento, prevaleceu. Venceu a proposta de reformar o Banco, mas já se distanciando da marca de banco de fomento para abrir a possibilidade de financiamento a empresas privadas e promover as exportações, com o objetivo de fazer frente aos déficits do balanço de pagamentos. Entre 1982 e 1986, em média, o Banco destinou $25,4 \%$ do total dos créditos desembolsados ao saneamento de empresas, preparando -as para a privatização, no caso das de propriedade estatal, ou, quando se tratava de empresas privadas, torná-las competitivas em mercados mais amplos (Curallero, 1998, p. 49).

Para desempenhar esse novo papel, foi promovida ampla reforma organizacional na estrutura do Banco. A fusão de suas subsidiárias (IBRASA, IBRAMEC e FIBASE) como BNDES Participações (BNDESPAR) permite a participação do BNDES no capital social de empresas consideradas prioritárias, mas sempre como sócio minoritário e sem direito a voto. A BNDESPAR constitui-se, dessa forma, como um canal de transferência de recursos públicos para o saneamento de empresas deficitárias. $\mathrm{O}$ Banco financiava até $70,0 \%$ do valor de venda da empresa a ser privatizada (DINIZ, 2004, p. 56). Esse conjunto de reformas permite considerar os anos 1980 como de mudança de rumo

${ }^{3}$ Do Plano de Governo de Fernando Collor de Mello (1990 a 1992) constava o estabelecimento de um Banco para Comércio Exterior, como parte da política de apoio à produção de longo ciclo e voltada para a exportação. Por sua curta vigência, o governo Collor de Mello não levou a cabo a criação do referido Banco. Especulava-se, ainda, sobre uma possível transformação do BNDES em banco dessa natureza, sob o comandado da iniciativa privada. 
na história do Banco, quando ele se torna um dos agentes da mudança patrimonial do Estado brasileiro, via privatização das empresas estatais, e de apoio às estratégias de produção voltadas para exportação.

O Plano Nacional de Desestatização (PNB), anunciado em 1990, é seguido do Programa de Privatização do BNDES, quando o Banco assume a posição no Conselho Federal de Desestatização como gestor da privatização, responsável pelos recursos financeiros e administrativos. Atua como um dos financiadores do saneamento financeiro das empresas, tanto na fase de pré-privatização quanto no financiamento aos novos proprietários (Prado, 1993, p. 80). Até 1995, as privatizações estavam concentradas em setores industriais, em especial, siderúrgico, petroquímico e fertilizantes. Esse movimento, para Miranda e Tavares (1999, p. 339), propiciou que o Estado brasileiro articulasse a associação entre o grande capital nacional, empresas e bancos estrangeiros. $\mathrm{Na}$ conformação dos conglomerados, o BNDES, por meio dos leilões das privatizações, funcionou "[...] como árbitro desse novo processo de escolha dos vencedores." As privatizações, dessa forma, possibilitaram a reestruturação patrimonial de setores produtivos e de serviços no Brasil, não apenas pela transferência de amplos segmentos industriais e de serviços do controle público para o privado, como também foi oportunidade para o surgimento de conglomerados constituídos a partir da associação entre o grande capital nacional entre si, como também com empresas e bancos estrangeiros. As oportunidades surgidas com as privatizações permitem a ampliação e a expansão de grupos empresariais, com a diversificação para novas áreas de negócios, como ocorreu com empresas de construção civil que avançaram para setores como petroquímico, serviços de infraestrutura e siderurgia. Ainda segundo Miranda e Tavares (1999, p. 341), "Dentre os 30 maiores grupos brasileiros, 13 tinham em 1998 seus core-businesses principais em commodities." Grupos como Mariani, Odebrecht, Vicu- nha, Ultra, Ipiranga, entre outros, se expandiram para setores produtores de commodities, sejam industriais, extrativo-minerais, ou agroindustriais. Os bancos também encontraram, nas privatizações, espaços para a diversificação e a valorização patrimonial. No primeiro momento, têm participação em consórcios que adquiriram empresas industriais e, em seguida, nas aquisições no próprio setor bancário. Grandes grupos estrangeiros também fortaleceram sua presença na economia brasileira, aproveitando as oportunidades abertas pela mudança na legislação. Também passam a participar da rede de proprietários das empresas privatizadas os Fundos de Pensão de funcionários de empresas públicas.

Novos programas e novas linhas de financiamento, com vistas a apoiar exportações de empresas brasileiras, são implementados. Em 1990, foi constituído o Programa de Financiamento às Exportações de Máquinas Equipamentos (FINANEX). Visando a facilitar o processo de contratação do crédito, em 1993, foi criada a linha Pagamentos e Créditos Recíprocos (CCR). Nesse caso, não é exigido o aval de um agente financeiro brasileiro, ficando o risco com o Banco Central do Brasil, no caso de crédito para exportação.

Em 1997, foi instituído o BNDES-Exim, que amplia a lista dos bens financiáveis, contemplando, além dos bens de capital, produtos intermediários e bens de consumo imediato. Os serviços de engenharia passam também a ser considerados e assumem posição de destaque nos desembolsos do Banco, em virtude das obras de infraestrutura que as construtoras brasileiras passam a executar em muitos países. O BNDES-Exim, já refletindo a experiência acumulada pelo Banco, no decorrer da década, no fornecimento de crédito para exportação, amplia as possibilidades de financiamento para praticamente todos os setores de produção e serviços.

A aproximação com empresas privadas coloca a exigência de medidas com objetivo de assegurar garantias de crédito, das quais 
são exemplos: a articulação com a Seguradora Brasileira de Créditos, do Fundo de Garantia às Exportações, criada para garantir cobertura dos riscos de responsabilidade da União; o Fundo de Garantia às Exportações, vinculado ao Ministério da Fazenda e gerido pelo BNDES; a adesão ao modelo Knaepen Package, da OCDE, para avaliação de risco (Alves, 2008, p. 72-73).

No plano organizacional, inciativas visando à atuação internacional são verificadas. A partir de 2002, um conjunto de medidas, um novo estatuto e decretos vão, legalmente, configurar o Banco em direção à internacionalização. Em 2009 e 2013, o BNDES abre escritórios de representação em Montevidéu e na África do Sul, respectivamente, que, embora não sejam autorizados a realizar operações, constituem ponto de apoio para articulações com atividades do Banco no âmbito da América Latina e do continente africano. Também em 2009, foi inaugurada a subsidiária de Londres, com atividades voltadas para o mercado financeiro. Os estatutos definem ainda que o BNDES pode: financiar a aquisição de ativos e investimentos no exterior, desde que isso seja realizado por empresas de capital nacional; contratar e prestar serviços técnicos e financeiros - inclusive não-reembolsáveis - visando ao desenvolvimento nacional e à integração da América Latina; captar recursos externamente ๑ para financiar investimentos no exterior, des-

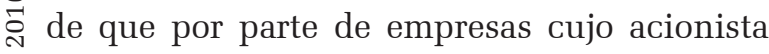
fi majoritário seja domiciliado no Brasil; adquirir participação acionária dessas empresas. Foi só em 2011 que se consolidou a possibilidade de o BNDES gerenciar operações de financiamento com origem e aplicação de recursos exclusia vamente externos. O Banco é também autoriiे zado, via decreto, a captar recursos no exterior para financiar projetos também no exterior, desde que realizados por empresas brasileiras e (ou) estrangeiras controladas por nacionais. Além disso, autoriza a aquisição de títulos dessas empresas, abrindo a possibilidade de compartilhamento de riscos do empreendimento com o Banco.
A administração de $40 \%$ dos recursos do Fundo de Amparo ao Trabalhador (FAT), se, por um lado, pode inibir a ampliação de ações no exterior, dada a natureza desse Fundo, destinado a gerar emprego no território brasileiro, por outro lado, proporcionou ao Banco a manutenção de um funding estável, que constitui base permanente para suas operações e ampliação.

\section{A INTERNACIONALIZAÇÃO DE EM- PRESAS BRASILEIRAS DE CONS- TRUÇÃO CIVIL E A EXPANSÃO PARA A AMÉRICA DO SUL}

A crescente presença de empresas brasileiras do ramo de construção civil, nas últimas décadas, em países sul americanos, é, por um lado, resultado da sintonia das empresas com a estratégia geopolítica do país, que combina decisões diplomáticas nos campos da política e da economia e sinaliza para as áreas prioritárias de valorização do capital produtivo. Por outro lado, é também resultado de estratégias empresariais definidas no âmbito das empresas que detêm domínio do conjunto das atividades da cadeia produtiva, adquirido ao longo de décadas no contexto do projeto desenvolvimentista.

\section{Desenvolvimento e internacionalização de empresas de construção civil no Brasil: um pouco da história}

A constituição do ramo da indústria de construção civil, especialmente seu setor de construção pesada e montagem industrial, hoje com presença internacional, tem origem na atuação de "mãos dadas" de empresas criadas a partir de capital familiar regional e atividades no âmbito das suas respectivas regiões com a máquina estatal brasileira na construção da infraestrutura e montagem de plantas industriais na trajetória de desenvolvimento da economia brasileira. O projeto desenvolvimentista, acelerado a partir dos anos 1950, 
exige a construção de hidroelétricas, linhas de distribuição de energia, serviços de telecomunicações, construção e pavimentação de rodovias que viabilizassem a circulação das mercadorias e a efetivação de um mercado interno integrado, construção e modernização de portos e aeroportos, como também a montagem de plantas industriais mais complexas, que exigiam especializados serviços de engenharia. A consequente urbanização passa a demandar obras de saneamento, abertura de novas vias de circulação, habitação e equipamentos de lazer (os estádios de futebol são os exemplos mais notórios). A modernização do setor agrícola, que marca os anos 1970, também demanda obras como construção de canais e montagem de equipamentos de irrigação.

A gama de atividades que envolveu o empreendimento desenvolvimentista possibilitou que parte das empresas viessem a dominar o conjunto de segmentos que compõe a cadeia produtiva da construção civil: edificações residenciais e comerciais urbanas; construção pesada; montagens industriais; e serviços especiais de suporte.

A lista das empresas mais internacionalizadas no ramo da construção civil destaca as seguintes:

- Andrade Gutierrez, criada em Minas Gerais em 1948, que ganha porte à sombra das obras levadas a cabo nos governos de Juscelino Kubitschek, seja em seu estado natal, como Governador, seja no âmbito do território nacional, quando Presidente da República. Individualmente ou de maneira associada, participou da construção das Hidroelétricas de Itaipu e Salto Osório, do aeroporto de Confins e da Ferrovia do Aço, entre tantas outras grandes obras.

- Mendes Jr., também mineira, com laços com estatais como a Companhia Energética de Minas Gerais e FURNAS, empresa geradora e transmissora de energia, estabelece contatos no setor de energia, sendo uma das empresas que participa da construção de Itaipu. A atuação junto à Petrobras levou essa empresa a construir refinarias e plataformas.

- Construtora Norberto Odebrecht, originada na Bahia, com enraizamento regional e com as agências estatais voltadas para a promoção do desenvolvimento da região, a exemplo do Departamento de Obras Contra a Seca (DNOCS), da Superintendência do Desenvolvimento do Nordeste (SUDENE) e do Banco Nacional do Nordeste, atua na construção de muitas obras na região. Dentre seus principais clientes está a Petrobras, que, à época, concentrava as atividades de extração e refino de petróleo na Bahia. Não deixa de ser significativo que a sede nacional da Petrobras (Rio de Janeiro) e a sede regional da Bahia tenham sido construídas por essa construtora, como também a Refinaria Landulfo Alves, a primeira refinaria de petróleo do país. A partir dos anos 1980, passa também a construir plataformas de extração de petróleo.

- Camargo Corrêa, criada em 1953, também tem origem em estado nordestino (Pernambuco). Construiu trechos da Transamazônica, a ponte Rio-Niterói, o metrô de São Paulo, para citar alguns exemplos;

- OAS Empreendimentos tem origem na Bahia, em 1976, ligada à família do então governador do estado, indicado pelos militares no período da ditadura. A partir dessa base, passa a ganhar concorrências públicas no próprio estado e em estados vizinhos (Campos, 2012).

Um exame da malha rodoviária brasileira, da produção e distribuição de energia elétrica, da infraestrutura urbana, da montagem de grandes empreendimentos industriais e da construção de habitação a partir de programas governamentais permite encontrar a marca das empresas acima citadas. São empresas que, à sombra do aparelho de Estado, constituíramse como oligopólios líderes na construção civil. É a partir da ação conjugada entre domínio tecnológico e organizacional para atuar em mercados externos e sintonia com a política externa e sua diplomacia, que tais empresas alcançaram o mercado internacional

Os anos 1970 são um marco para a interna- 
cionalização de empresas de construção civil brasileiras, como parte de um movimento que deixa de ser orientado pela realização de obras pontuais, de uma ou outra empresa, para mover-se a partir de estratégias empresariais de longo prazo e sintonizadas com a geopolítica que passa a orientar as relações externas do país. De acordo com dados da Fundação João Pinheiro, citados por Cristaldo (2011, p. 114), entre 1970 e 1980, a exportação de serviços de engenharia - estudos e projetos, construção, montagem industrial e serviços especializados - celebrados por empresas brasileiras somou 444 contratos no exterior, com $75 \%$ do total concentrado em países sul-americanos e países africanos, correspondendo a 53\% e $22 \%$, respectivamente.

As crises do petróleo, ao longo dessa década, com consequências sobre o balanço de pagamentos, levou o Itamaraty, durante o governo Geisel, a negociar com o Iraque a troca de petróleo por serviços de engenharia. Fruto dessa negociação, a Mendes Júnior construiu, naquele país, uma ferrovia, uma rodovia e obras de uma estação de bombeamento no Rio Eufrates. Para além da conjuntura da crise e do desequilíbrio da balança comercial, o episódio significa abertura de mercado de construção civil em países do Oriente Médio para outras empreiteiras brasileiras, com atuação na região até os dias atuais. A expansão de empresas de construção civil nessa direção também está fi associada à presença da Petrobras no Oriente Ŝ̉ Médio e na África (Irã, Líbia, Argélia, Madagáscar e Mauritânia), para explorar novas fon今े tes supridoras de petróleo (Campos, 2012). \& ras de construção civil na África date de perío今 dos anteriores, a inclinação da política externa $\therefore$ brasileira, voltada para priorizar articulações Sul-Sul, favorece que sejam realizados novos contratos em países africanos. A Andrade Gutierrez está presente em Angola, Argélia, Congo, Camarões, Mauritânia, Guiné-Conacri e Guiné Equatorial. A Odebrecht mantém projetos em Angola desde 1984, com 28 projetos em execução em 2012. No Sudão e em Gana, essa construtora está envolvida em empreendimentos de etanol, além de Moçambique com a infraestrutura da mina de Moatize, de propriedade da Vale, e a construção do Aeroporto de Nacala. A empresa Camargo Corrêa esta presente em Guiné, Moçambique e Angola.

O histórico de realização de grandes obras por empreiteiras brasileiras em países sul-americanos foi intensificada, nas últimas décadas, com as iniciativas de governos da região de promover a integração da América do Sul. É em países dessa região que empreiteiras brasileiras intensificaram a realização de obras no exterior. A Mendes Júnior, a primeira empresa do ramo a se internacionalizar, construiu, entre 1969 e 1973, a Hidroelétrica de Santa Isabel em Cochabamba, Bolívia. Em 1989, passou a atuar no Chile, quando iniciou a expansão da mina de cobre Los Bronces. Ainda nesse país, são registradas obras como o metrô de Santiago, a estação de tratamento de água La Florida, a construção dos Túneis Corrales e da Placaro (www.mendesjunior. com.br). A Camargo Corrêa registra obras na Venezuela, com a construção da Hidroelétrica de Guri, e a Represa de Tuy IV; no Peru, com a construção da Rodovia Interoceânica, da adutora de Huachipa e do túnel e Represa no Alto Piura; na Argentina, a construção da represa Ete de Beratequi (www.camargocorrea. com.br). A Andrade Gutierrez exibe, em seu portfolio, como as principais obras na região: Siderúrgica Nacional da Venezuela, Aeroporto Internacional de Quito, Projeto Bayóvar e Interoceânica Sul (ligação entre o Brasil e Peru), no Peru (www.andradegutierrez.com.br ). A OAS Empreendimentos registra a construção de estradas na Bolívia, obras de saneamento no Chile e rede de distribuição de gás no Uruguai (www.oasempreendimentos.com.br). A Construtora Norberto Odebrecht, com atuação em muitos países da América do Sul, cita como as principais obras por país: Argentina (desde 1987), a construção da Hidrelétrica Pichi Pucún Leufú, o Projeto Potássio Rio Co- 
lorado, Gasoduto San Martin, subterrâneo do Soterramineto Sarmiento; Peru (desde 1993), Projeto de Irrigação e Chavimochic, Central Hidrelétrica Chaclla, Porto de Mararani; Equador (desde 1987), aqueduto La Esperanza e o poliduto Pascuales-Cuenca; Venezuela (desde 1992), Aeroporto Internacional Simon Bolívar, linhas de metrô, Central hidrelétrica Manuel Piar, além de obras de conjuntos residenciais. A Odebrecht tem também participação em obras da IRRSA Norte e IRRSA Sul, rota de ligação do Brasil com o Pacífico pelo Peru (www. odebrecht.com.br).

A natureza do produto da indústria de construção civil define um tipo de presença singular, se comparada com outras indústrias e empresas no local de produção: durante a execução da obra, faz-se necessária a existência da planta; concluída a obra, a planta é desfeita. A presença de uma empresa do ramo da construção civil em um país pode ter duração de curto prazo, ser passageira: o tempo de execução de uma determinada obra.

\section{Créditos do BNDES para exportações de serviços de engenharia para países da América do Sul}

Os contratos celebrados pelo BNDES, segundo dados disponibilizados pelo Banco, para realização de obras de construção civil em países da América do Sul, entre 2004 e 2016, totalizam US\$ 5. 504. 545. 846,00.

Os contratos realizados correspondem à execução de obras de infraestrutura na Venezuela, na Argentina e no Equador, representando a 59\%, 37\% e 4\%, respectivamente, do montante total de créditos (Tabela 1). Os dados referentes à Argentina e à Venezuela refletem a posição histórica dessas duas economias, que figuram como a primeira e a segunda colocada, respectivamente, entre as economias sul-americanas, depois do Brasil. Os dados relativos ao Equador registram o retorno da Construtora Norberto Odebrecht ao país, após a crise em
2008, quando a empreiteira brasileira foi expulsa por problemas técnicos apresentados na Hidroelétrica San Francisco.

Ainda de acordo com os dados disponibilizados pelo BNDES, a Construtora Norberto Odebrecht é a empresa com maior número de contratos e volume de operações no período, totalizando, aproximadamente, $61,5 \%$ do valor do total das operações realizadas. Detém a totalidade dos contratos no Equador, destinados à construção da Hidroelétrica de Mandurian e o projeto de Irrigação Transvase Daule Vinces. Na Venezuela, com três contratos para obras de mobilidade urbana - construção de linhas do metrô de Caracas e Los Teques - detém 33,0\% do valor dos contratos celebrados para realização de obras naquele país. É na Argentina que participação dessa construtora, no valor total, atinge maior percentual, representando 88,0\%, em obras voltadas para distribuição e tratamento de água e distribuição de gás.

A Andrade Gutierrez aparece como a segunda empresa em volume de créditos, com a realização de dois grandes projetos na Venezuela - construção da Usina Siderúrgica Nacional e implantação de estaleiro para construção e manutenção de embarcações - representado, aproximadamente, 67,0\% do valor dos contratos no país. A Camargo Corrêa e a Construtora OAS têm atuação na Argentina, realizando projeto de construção de plantas de abastecimento de água e construção de aqueduto, respectivamente.

Chama a atenção que, entre os contratos, não sejam registradas obras planejadas pela Iniciativa para a Integração da Infraestrutura Regional Sul-americana (IIRSA), indicadas como eixos de integração. Isso, cumpridos dez anos que a Iniciativa veio a público e cinco após da Agenda de Implementação Consensuada, que definiu os projetos de prioritária execução até 2010. Bem entendido, esse registro não significa que não estejam sendo realizadas obras dessa Iniciativa, mas que não estão entre os projetos com financiamento do BNDES. 
Tabela 1 - Operações contratadas pelo BNDES com empresas brasileiras de construção civil para exportação de bens e serviços para atuação na América do Sul - 2004/2015

\begin{tabular}{|c|c|c|c|c|c|}
\hline Empresa & País & $\begin{array}{c}\text { Ano de } \\
\text { Liberacấo }\end{array}$ & Projetos & Valor & $\%$ \\
\hline \multicolumn{4}{|l|}{$\begin{array}{l}\text { Construtora } \\
\text { Norberto Odebrecht }\end{array}$} & 3.396.018.123,00 & 61,7 \\
\hline & \multicolumn{3}{|l|}{ Argentina } & $1.809 .428 .528,00$ & \\
\hline & & 2005 & $\begin{array}{l}\text { Ampliação da capacidade de transporte do gasoduto } \\
\text { San Martin }\end{array}$ & $148.428 .678,00$ & \\
\hline & & 2007 & $\begin{array}{l}\text { Ampliaçáo da capacidade de transporte da rede de gasoduto } \\
\text { troncais de TGS e TGN }\end{array}$ & $436.396 .969,00$ & \\
\hline & & 2007 & $\begin{array}{l}\text { Ampliaçáo da capacidade de transporte de gás natural das } \\
\text { malhas dos gasodutos operados por TGS e TGN }\end{array}$ & $636.884 .286,00$ & \\
\hline & & 2010 & $\begin{array}{l}\text { Construçăo da planta de tratamento e de sistema de águas } \\
\text { de Paraná a Las Palmas }\end{array}$ & $293.866 .532,00$ & \\
\hline & & 2010 & Apliação do Gasoduto San Martin & $226.058 .182,00$ & \\
\hline & & 2012 & Apliação do Gasoduto San Martin & $67.793 .881,00$ & \\
\hline & \multicolumn{3}{|l|}{ Equador } & 227.197.110,00 & \\
\hline & & 2012 & Construção de Usina Hidroelétrica Manduriacu & $90.226 .703,00$ & \\
\hline & & 2013 & Projeto de Irrigação Transvase Daule e Vinse & $136.970 .407,00$ & \\
\hline & Venezuela & & & $1.359 .392 .485,00$ & \\
\hline & & 2004 & $\begin{array}{l}\text { Construçäo trecho El Valle-Rinconada, três estaçōes e ura } \\
\text { intercâmbio intermodal: Linha } 3 \text { de Metrô Caracas }\end{array}$ & $78.000 .000,00$ & \\
\hline & & 2009 & Construçăo da Linha 3 do Metrô Los Teques & $527.847 .704,00$ & \\
\hline & & 2009 & Construção da Linha 5 do Metrô Caracas & $219.342 .333,00$ & \\
\hline & & 2015 & Construção da Linha 5 do Metrô Caracas & $200.000 .000,00$ & \\
\hline & & 2015 & Construçäo da Linha 2 do Metrố Los Teques & $334.202 .448,00$ & \\
\hline \multicolumn{4}{|l|}{ Andrade Gutierres } & $1.503 .317 .584,00$ & $\mathbf{2 7 , 3}$ \\
\hline & \multicolumn{3}{|l|}{ Venezuela } & 1.503.317.584,00 & \\
\hline & & 2010 & Construção de Usina Siderúrgica Nacional no Estado de Bolívar & $865.423 .450,00$ & \\
\hline & & 2011 & $\begin{array}{l}\text { Implantaçăo de um estaleiro para construçâo, reparos e } \\
\text { manutençăo de embarcaçóes }\end{array}$ & $637.894 .134,00$ & \\
\hline \multicolumn{4}{|l|}{ Camargo Coxrêa } & 414.595.517,00 & 7,5 \\
\hline & \multicolumn{3}{|l|}{ Argentina } & $45.657 .374,00$ & \\
\hline & & 2011 & Implantação das plantas de abastecimento das cidades de & $45.657,374,00$ & \\
\hline & Venezuela & & & 368.938.143,00 & \\
\hline & & 2015 & $\begin{array}{l}\text { Projeto de saneamento e desenvolvimento integral da Bacia } \\
\text { do Rio Tuy }\end{array}$ & $368.938 .143,00$ & \\
\hline \multicolumn{4}{|l|}{ Construtora OAS } & $165.022 .672,00$ & $\mathbf{3 , 0}$ \\
\hline & \multicolumn{3}{|l|}{ Argentina } & $165.022 .672,00$ & \\
\hline & & 2011 & Construção do segundo aqueduto para o interior do Chaco & $165.022 .672,00$ & \\
\hline \multicolumn{4}{|l|}{ Confab Industrial S/A } & $25.591 .950,00$ & 0,5 \\
\hline & \multicolumn{3}{|l|}{ Argentina } & $25.591 .950,00$ & \\
\hline & & 2005 & $\begin{array}{l}\text { Ampliação da capacidade de transporte do gasoduto General } \\
\text { San Martin }\end{array}$ & $25.591 .950,00$ & \\
\hline \multicolumn{4}{|l|}{$\begin{array}{l}\text { Bureau de } \\
\text { Projetos e Consultoria } \\
\text { Ltda }\end{array}$} & 0,00 & 0,0 \\
\hline & \multicolumn{5}{|l|}{ Argentina } \\
\hline & & 2011 & Projeto de Engenharia Túnel Água Negra & $15.990 .535,00$ & \\
\hline \multicolumn{4}{|l|}{ TOTAL } & $5.504 .545 .846,00$ & 100 \\
\hline
\end{tabular}

if Fonte: BNDES - www.bndes,govbr (acesso em 02. 03.2016)

\section{CONCLUSÕES}

A concessão de créditos pelo BNDES a nas últimas décadas; ações governamentais empresas brasileiras de construção civil para a orientadas pela decisão de intensificar as rerealização de obras no exterior é resultado de lações Sul-Sul, especialmente em relação aos movimento que contempla: exigências de sin- países da porção Sul do continente americano; tonia entre os processos de valorização dos ca- e estratégias empresariais que visam à amplia- 
ção dos espaços de atuação.

É nesse contexto que são implementadas as reformas institucionais e organizacionais no BNDES, que vão permitir atuações conectadas com regras do mercado como emprestador e como captador de recursos. A abertura de representações no exterior, desempenhando diferentes papéis, atende a essa diretriz. Novas linhas de créditos são desenhadas visando ao fortalecimento das empresas que, no contexto nacional, tenham acumulado domínio tecnológico e organizacional e sejam capazes de atuar além-fronteiras, como é o caso das empresas de construção civil aqui analisadas.

Recebido para publicação em 15 de outubro de 2015 Aprovado em 21 de novembro de 2015

\section{REFERÊNCIAS}

ALVES, Rodrigues Maschion. A temática financeira na agenda política do governo Lula: o BNDES e o modelo de participação e exposição financeira do Brasil na América do Sul. Dissertação, 2008. Programa San Tiago Dantas, UNESP-UNICAMP e PUC SP, São Paulo.

ARAÚJO, Victor Leonardo et al. La experiencia brasileña con bancos de desarrollo: el caso del Banco Nacional de Desarrollo Económico y Social de Brasil. In: M. Rougier (Comp.) La Banca de Desarrollo en América Latina: luces y sombras en la industrialización de la región. Buenos Aires: Fondo de Cultura Económica, 2011.

CAMPOS, Pedro Henrique Pedreiras. A ditadura dos empreiteiros: as empresas nacionais de construção pesada, suas formas associativas e o Estado ditatorial brasileiro, 1964-1985. Tese. Niterói. Programa de Pós-Graduação de História Social da Universidade Federal Fluminense, 2012.

CRISTALDO, Rômulo Carvalho. A indústria brasileira de construção civil entre 1974 e 1979: constituição das bases nacionais para o processo de internacionalização. Dissertação. 2011, Programa de Pós-Graduação em Administração. UFBa. Salvador.

CURRALER, Claudia Regina Baddini. A Atuação do Sistema BNDES como Instituição Financeira de Fomento no Período 1952/1996. Dissertação. 1998. Instituto de Economia, UNICAMP, Campinas.

DEOS, Simone S. de; WEGNER, Rubia. Cooperação Financeira e o Financiamento da Infraestrutura na América do Sul. OIKOS, Rio de Janeiro, v. 9, n. 2, p. 69-98, 2010.

DINIZ, Adriana Nascimento. BNDES: de agente desenvolvimentista a gestor da privatização - 1952-2002. Dissertação. 2004. Instituto de Economia, UNICAMP. Campinas.

GARCIA, Ana Saggioro. A internacionalização de empresas brasileiras durante o governo Lula: uma análise crítica da relação entre capital e Estado no Brasil contemporâneo. Tese. 2012. Pontifícia Universidade Católica do Rio de Janeiro. Rio de Janeiro.
GUDYNAS, Eduardo As instituições financeiras e a integração na América do Sul, In: R. Verdum (Org.) Financiamento e Megaprojetos: uma Interpretação da Dinâmica Regional Sul-Americana. Brasília: INESC, 2008.

HERMANN, Jeniffer. Los bancos de desarrollo en la "era de la liberalización financiera": el caso del BNDES en Brasil. Revista CEPAL, Santiago do Chile, n.100, p. 193-208, 2010.

KRAYCHETE, Elsa Sousa; CRISTALDO, R. C. The National Bank of Economic and Social Development on the Brazilian Develeopment strategies: fron internal artuculation to expansionto Latin América. Geopolitica(s): revista de estudios sobre espacio y poder. v. 4, n. 1, p. 63-86, 2013.

LIMA, Maria Regina Soares de. Relações interamericanas: a nova agenda sul-americana e o Brasil. Lua Nova, São Paulo, n. 90, p. 167-201 set./dez., 2013

MIRANDA, José Carlos; TAVARES. Maria da Conceição. Brasil: estratégias da conglomeração. In: FIORI, José Luis (org.) Estados e moedas no desenvolvimento das nações. Petrópolis/RJ: Editora Vozes, 1999.

MUSACCHIO, Aldo; LAZZARINI, Sérgio. Reinventando o capitalismo de Estado: o Leviatã nos negócios. Brasil e outros países. São Paulo: Portfólio-Penguim, 2015.

NIKO, Diego. Integração regional, cooperação financeira e a atuação do BNDES na América do Sul no Período Recente. Dissertação. 2011. Instituto de Economia, UNICAMP, Campinas.

STALLINGS, Bárbara. Financiamiento para el Desarrollo América Latina desde una Perspectiva Comparada. Santiago do Chile: CEPAL, 2006.

RUTTIMAN, André de Barros et al. CCR: seu papel no financiamento à infraestrutura. Revista do BNDES, Rio de Janeiro, n 29, p. 81-114, jun., 2008.

TAUZ, Carlos et al . O BNDES e a Reorganização do Capitalismo Brasileiro: um debate Necessário, In. Os Anos Lula: Contribuições para um Balanço Crítico 2003-2010. Rio de Janeiro: Garamond, 2010.

TORRES FILHO, Ernani Teixeira; COSTA, Fernando Nogueira da. BNDES e o Financiamento do Desenvolvimento. Economia e Sociedade, Campinas, v. 21, n. Especial, p. 975-1009, 2012.

\section{Sites}

www.andradegutierrez.com.br

www.bndes.gov.br

www.camargocorrea.com.br

www.mendesjunior.com.br

www.oasempreendimentos.com.br

www.odebrecht.com.br 


\section{THE NATIONAL BANK FOR ECONOMIC AND SOCIAL DEVELOPMENT (BNDES) AND THE EXPANSION OF BRAZILIAN CIVIL CONSTRUCTION COMPANIES TO SOUTH AMERICA}

\author{
Elsa Sousa Kraychete
}

This article presents the credit agreements granted by the National Bank for Economic and Social Development between 2004 and 2015, aimed to support the export of engineering services to countries in South America, broken down by company, country, work performed and contract value. The data analysis is accompanied by the history of institutional changes experienced by the Bank in recent decades. The conclusion is that the granting of credit to Brazilian construction companies to carry out works abroad is the result of a broad movement that includes synchrony requirements between the capital value processes and the regulation mode facing the big changes that capitalism suffered in recent times; governmental actions guided by the decision to strengthen SouthSouth relations, particularly in the countries of the southern portion of the American continent; and business strategies aimed at expanding the areas of action.

KeYwords: National Bank for Economic and Social Development, credit, civil construction companies, Brazil, South America.

\section{LA BANQUE NATIONALE DE DÉVELOPPEMENT ÉCONOMIQUE ET SOCIAL (BNDES) ET L'EXPANSION DES ENTREPRISES BRÉSILIENNES DE CONSTRUCTION CIVILE POUR L'AMÉRIQUE DU SUD}

\author{
Elsa Sousa Kraychete
}

Cet article présente les contrats de crédits accordés par la Banque Nationale de Développement Economique et Social, entre 2004 et 2005, visant à soutenir l'exportation de services d'ingénierie pour les pays d'Amérique du Sud; il sont classés par entreprise, pays, travaux effectués et valeur de contrat. L'analyse des données est accompagnée de l'historicisation des changements institutionnels qui ont eu lieu au sein de la Banque au cours des dernières décennies. La conclusion est que l'octroi de crédits aux entreprises de construction brésiliennes pour la réalisation de travaux à l'étranger est l'aboutissement d'un large mouvement qui comprend des exigences d'accord entre les processus de valorisation des capitaux et la réglementation face aux grands changements récents du capitalisme, des actions gouvernementales guidées par la volonté d'intensifier les relations sud-sud, tout particulièrement dans les pays de la partie méridionale du continent américain, et des stratégies d'affaires en vue d'une amplification du rayon d'action.

Mot-CLÉs: Banque Nationale de Développement Économique et Social, crédit, entreprises de construction civile, Brésil, Amérique du Sud.

Elsa Sousa Kraychete - Doutora em Administração. Professora do Instituto de Humanidades, Artes e Ciências Professor Milton Santos da UFBa, atuando nos cursos de Pós-graduação em Relações Internacionais e Administração (NPGA). Editora científica do Caderno CRH. Pequisadora no Programa Pesquisador UFBa de Produtividade CNPQ(PROPI) PROPI/2013. Suas pesquisas recentes tratam dos temas do desenvolvimento e da cooperação internacional. Publicações recentes: O Brasil e a Cooperação Sul-Sul: dilemas e desafios na América do Sul. Salvador: Edufba, 2015; Desenvolvimento e cooperação internacional: relações de poder e política dos Estados, Salvador: Edufba, 2014; Dicionário Temático Desenvolvimento e Questão Social: 81 problemáticas contemporâneas. São Paulo: Annablume Editora, 2013; Cooperação Internacional para o Desenvolvimento: desafios no século XXI. Salvador: Edufba, 2013. 